\title{
Comparison of Safety and Efficacy of ProSeal Laryngeal Mask Array vs Endotracheal Intubation for Gynecological Diagnostic Laparoscopy
}

\author{
${ }^{1}$ Valmik Avhad, ${ }^{2}$ Shrikanta Oak, ${ }^{3}$ Anita Shetty
}

\begin{abstract}
This was a prospective randomized study comparing the safety and efficacy of ProSeal laryngeal mask array (PLMA) vs endotracheal intubation (ETT) in gynecological laparoscopic surgeries undertaken in 80 patients with American Society of Anesthesiologist I and II divided into two groups. The parameters assessed were insertion characteristics, hemodynamic response to insertion, gastric distension, and perioperative complications.

The demographic data were comparable. The first-time success rate was slightly higher for PLMA than for ETT. The time required for achieving effective airway was longer in ETT than in PLMA (25.6 \pm 8.1 seconds for ETT vs $18.2 \pm 5$ seconds for PLMA).

The hemodynamic response to intubation/insertion was more in ETT group than in PLMA group, i.e., there was more rise in pulse rate and mean arterial pressure following ETT than PLMA insertion.

Intraoperatively, no episodes of laryngospasm, bronchospasm, desaturation, and inadequate ventilation were observed in both the groups. Postoperatively, sore throat complaints were observed more with ETT than with PLMA.
\end{abstract}

Keywords: Endotracheal tube, Hemodynamic parameters, Laparoscopic surgery, ProSeal laryngeal mask array.

How to cite this article: Avhad V, Oak S, Shetty A. Comparison of Safety and Efficacy of ProSeal Laryngeal Mask Array vs Endotracheal Intubation for Gynecological Diagnostic Laparoscopy. Res Inno in Anesth 2017;2(1):9-13.

Source of support: Nil

Conflict of interest: None

\section{INTRODUCTION}

Laparoscopic surgery is an evolving subspecialty with problems of carbon dioxide insufflation, raised abdominal pressure, and danger of regurgitation and pulmonary aspiration. Thus, airway management continues to be of paramount importance to anesthesiologists in order

\footnotetext{
${ }^{1}$ Assistant Professor, ${ }^{2}$ Associate Professor, ${ }^{3}$ Professor

${ }^{1-3}$ Department of Anesthesia, King Edward Memorial Hospital and Seth Gordhandas Sunderdas Medical College, Mumbai Maharashtra, India

Corresponding Author: Valmik Avhad, Assistant, KH-3/3/502 Sanskruti Chs Sector-16, Vastuvihar Kharghar, Navi Mumbai Maharashtra, India, e-mail: valmikavhad@gmail.com
}

to maintain adequate ventilation. Till date, the cuffed endotracheal tube (ETT) was considered as the gold standard for providing a safe glottis seal, especially for laparoscopic surgeries under general anesthesia. ${ }^{1}$ Disadvantages of tracheal intubation include hemodynamic responses to laryngoscopy and damage to the oropharyngeal structures at insertion along with postoperative sore throat. Thus, new airway devices have been added to the anesthesiologist's armamentarium.

"ProSeal laryngeal mask array (PLMA)" modification of Classic LMA is a useful tool in airway management. It differs from standard LMA having a drain tube in addition to a reinforced airway tube, which prevents the epiglottis from occluding the airway. It eliminates the use of aperture bars and prevents inadvertent gastric inflation. The additional dorsal cuff increases the seal, allowing higher seal than the standard LMA, for a given intracuff pressure. The built-in bite-block reduces the chances of damage to device by inadvertent biting by the teeth of the patient and danger of airway obstruction. It can be inserted using an introducer or the finger. ${ }^{2}$

Our study is to compare PLMA and laryngoscopic tracheal intubation for diagnostic laparoscopy in terms of ease of insertion, time taken for insertion, perioperative hemodynamic changes, oxygenation, ventilation, and perioperative laryngopharyngeal complications.

\section{MATERIALS AND METHODS}

This was a randomized prospective study conducted after the approval from the Institutional Ethics Review Board. The study involved comparison between PLMA and the ETT for gynecological laparoscopic surgery with respect to (1) time taken to secure airway; (2) perioperative hemodynamic response; (3) incidence of gastric distension and complications during perioperative period.

The study randomly allocated 80 patients in a tertiary care institute divided into two groups: Aged 18 to 65 years, posted for gynecological laparoscopy, American Society of Anesthesiologists (ASA) I and II, and weight 32 to $75 \mathrm{~kg}$. Patients with inadequate mouth opening (less than $2.5 \mathrm{~cm}$ ), morbidly obese, having disease with risk of aspiration like gastroesophageal reflux, hiatus hernia, 
oropharyngeal pathology, cervical spine injury were excluded from the study.

Eighty patients were randomly divided into group $\mathrm{P}$ (PLMA) and group E (ETT) using computer-generated lists.

After confirming adequate starvation, preoperative workup, and checking, patients who provided informed valid consent were taken inside the operation room. A senior anesthesiologist (minimum 1 year residency in anesthesia) was allowed to insert appropriate size PLMA (3 or 4 ) with cuff fully deflated and posterior surface lubricated with $2 \%$ xylocaine jelly using introducer or ETT size (7 or 7.5 ) by standard technique.

In both the groups, time taken for device insertion was noted (in seconds or minutes). Oropharyngeal seal pressure was determined by closing the expiratory valve of the circle system at a fixed gas flow of $4 \mathrm{~L} / \mathrm{min}$ and recording the airway pressure at which equilibrium was reached. The airway pressure was not allowed to exceed $30 \mathrm{~cm} \mathrm{H}_{2} \mathrm{O}$ by altering tidal volume and respiratory rate.

The following parameters were recorded perioperatively at regular intervals: Heart rate $(\mathrm{HR})$, mean arterial blood pressure (MAP, mm Hg), end-tidal $\mathrm{CO}_{2}\left(\mathrm{EtCO}_{2}\right.$, $\mathrm{mmHg})$, oxygen saturation $\left(\mathrm{SpO}_{2}\right)$. Duration of pneumoperitoneum, duration of anesthesia, and duration of surgery were recorded. For the most gynecological diagnostic laparoscopic procedures, the intraabdominal pressure was kept between 12 and $14 \mathrm{~mm} \mathrm{Hg}$. Gastric distension was recorded by laparoscopic camera as distended or not distended by operating surgeons.

The following complications were assessed: Gastric distension/insufflation hypercarbia and bronchospasm, sore throat.

\section{Statistical Analysis}

Sample size was calculated considering previous study using EPI calculator at openepi.com.

Results of the study were observed and analyzed statistically. Quantitative data were analyzed using Student's t-test and qualitative data were analyzed using chi-square test. Statistical difference was considered significant if $\mathrm{p}<0.05$.

\section{OBSERVATIONS AND RESULTS}

Groups were comparable with regard to all the demographic data like age, weight, and ASA grades. The mean age in group $\mathrm{E}$ was $27.8 \pm 3.6$ years and in group $\mathrm{P}$ was $30.1 \pm 6$ years and the mean weight in group $E$ was $52 \pm$ $5.5 \mathrm{~kg}$ and in group P was $55.1 \pm 4.3 \mathrm{~kg}$, and the difference was not statistically significant (Table 1).
Table 1: Time for acheiving effective airway (TFEA) (SEC) and number of attempts for securing airway

\begin{tabular}{llll}
\hline Parameter & ETT & PLMA & Significance \\
\hline TFEA (sec) & $25.6(8.1)$ & $18.2(5)$ & $<0.05 \mathrm{~S}$ \\
Attempts (1:2) & $7: 1$ & $5: 1$ & $>0.05 \mathrm{NS}$ \\
No. of attempts 1 & 33 & 35 & \\
No. of attempts 2 & 7 & 5 & \\
\hline
\end{tabular}

S: Significant; NS: Nonsignificant; TFEA: Time for achieving effective airway

The mean time required for achieving effective airway was longer in ETT than PLMA, which was statistically significant (Table 1).

\section{Pulse Rate in ETT and PLMA Groups}

When pulse rate is compared between ETT and PLMA groups at all the time intervals, statistically significant differences were observed at insertion, 1, 3, 5, and 10 minutes, after desufflation and extubation. At all these time intervals, the change in pulse rate was significantly less in PLMA group as compared with ETT group (Graph 1).

\section{Mean Arterial Pressure $(\mathrm{mm} \mathrm{Hg})$}

When ETT and PLMA groups were compared, MAP at insertion, 1 minute, after insufflation, after desufflation, and extubation were significantly different $(p<0.05)$. At these time intervals, MAP was significantly lower in PLMA group than in ETT group (Graph 2).

\section{End Tidal Carbon Dioxide}

When ETT was compared with PLMA group, EtCO values at 1, 3, 5 minutes, and after insufflations were significantly different between the groups $(\mathrm{p}<0.05)$. At all these time intervals, $\mathrm{EtCO}_{2}$ values were significantly higher in ETT than PLMA, but they are not clinically significant (Graph 3).

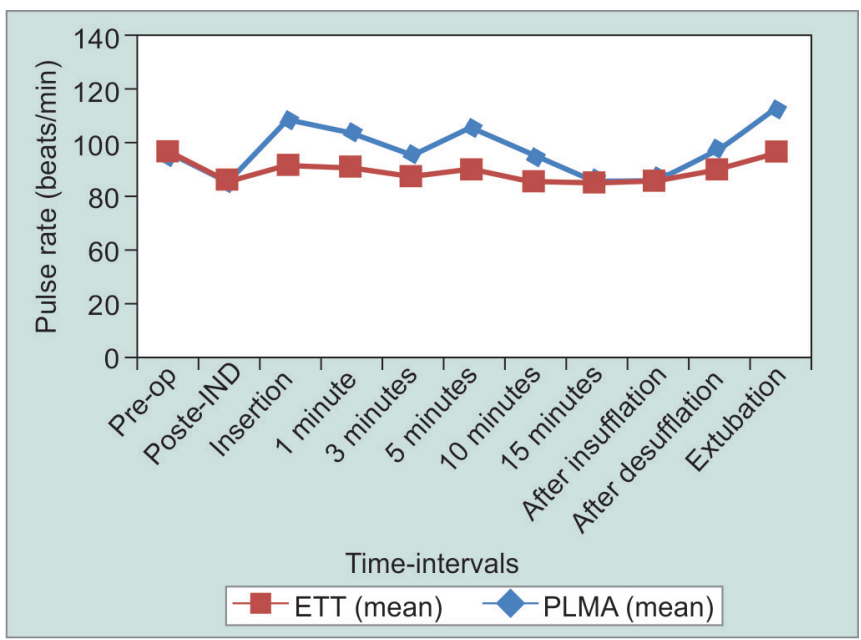

Graph 1: Pulse rate $(\mathrm{mm} \mathrm{Hg})$ at various time intervals in both ETT and PLMA group 


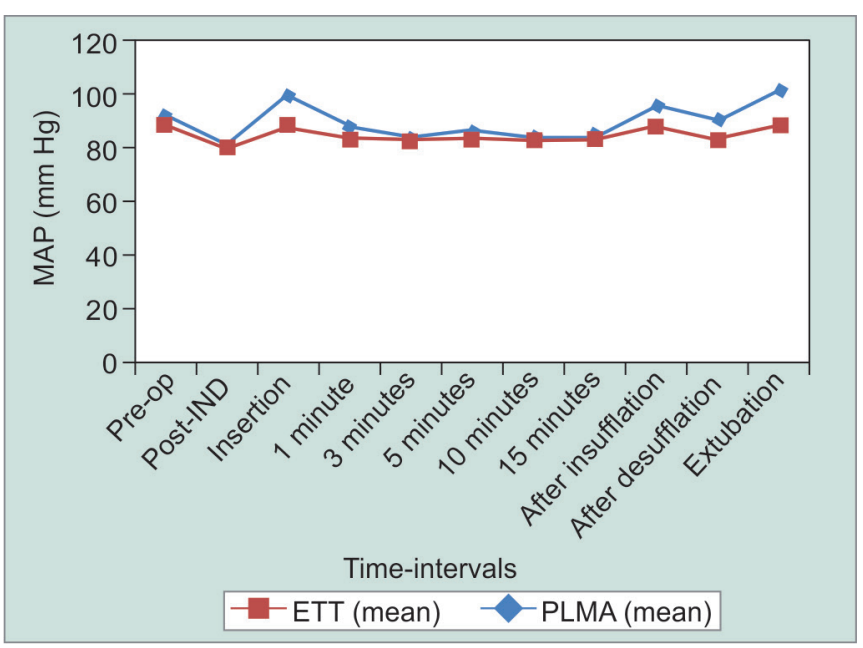

Graph 2: MAP ( $\mathrm{mm} \mathrm{Hg})$ at various time intervals in both ETT and PLMA group

\section{ADVERSE EFFECTS}

Gastric distension was observed intraoperatively after insufflation in six patients in ETT group and five patients in PLMA group (Table 2).

Postoperatively, in ETT group, nine patients had sore throat compared with three patients in PLMA group. This difference was found to be statistically significant. Sore throat complaints were of mild to moderate grade and none of them required active management.

\section{DISCUSSION}

Traditional open surgeries are progressing to minimally invasive laparoscopic surgeries, which helped to minimize surgical trauma and widened the scope for laparoscopy. ${ }^{3}$

The main anesthetic concerns during laparoscopic surgeries are:

- Achieving adequate ventilation and maintaining normocarbia.

- Avoiding regurgitation and aspiration, which may arise due to increased intraabdominal pressure.

- Attenuating the hemodynamic response associated with pneumoperitoneum. There is controversy regarding the optimal anesthetic technique for laparoscopy. ${ }^{4}$

Table 2: Gastric distension

\begin{tabular}{lllll}
\hline Gastric distension & & ETT & PLMA & Total \\
\hline Present & No. & 6 & 5 & 11 \\
& $\%$ & 14.3 & 12.5 & 15.9 \\
Absent & No. & 34 & 35 & 69 \\
& $\%$ & 85.7 & 87.5 & 84.1 \\
\hline
\end{tabular}

\begin{tabular}{lllll}
\hline $\begin{array}{l}\text { Chi-square } \\
\text { test }\end{array}$ & Value & $\begin{array}{l}\text { Degrees of } \\
\text { freedom (Df) }\end{array}$ & $p$-value & Association is \\
\hline $\begin{array}{l}\text { Pearson } \\
\text { chi-square }\end{array}$ & 1.7 & 1 & 0.6 & NS \\
\hline \multicolumn{2}{l}{$\begin{array}{l}\text { Not significant } \\
\text { r }\end{array}$} & & & \\
\hline
\end{tabular}

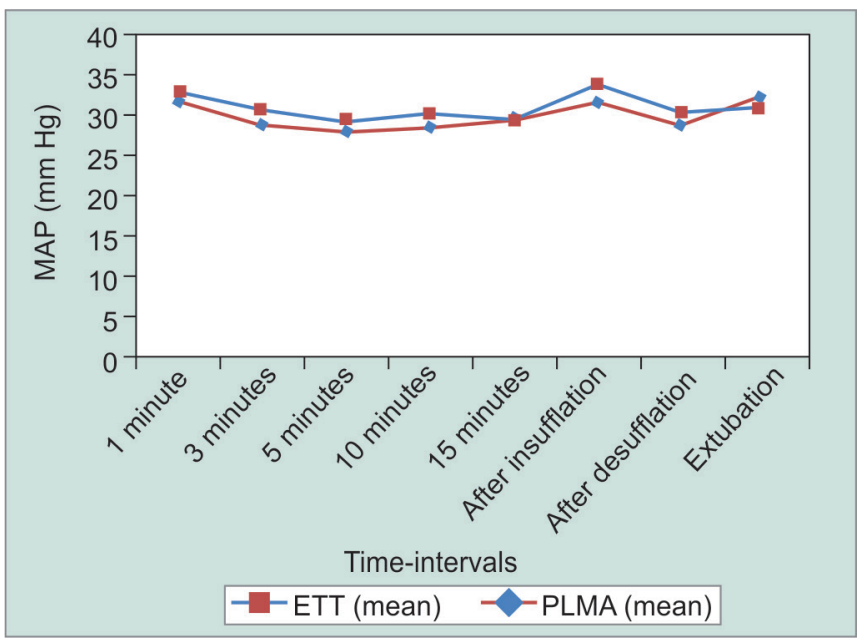

Graph 3: $\mathrm{EtCo} 2(\mathrm{~mm} \mathrm{Hg})$ at various time intervals in both ETT and PLMA groups .

Endotracheal tube is a rapid, simple, safe, and nonsurgical technique that achieves all goals of airway management, namely airway patency, protecting the lungs from aspiration, and permitting leak-free ventilation during mechanical ventilation, but associated with complications like arrhythmias and hypertension, respiratory complications (laryngospasm, bronchospasm, aspiration with or without regurgitation), and pneumonitis. The mechanical complications include oropharyngeal mucosal injury and laryngopharyngeal complications like sore throat (Table 3).

In our study, for both the groups, the first-time insertion success rates were comparable and statistically insignificant as seven cases in ETT group and five cases in PLMA group, which required two attempts. The time required for achieving effective airway was longer in ETT than PLMA, which was statistically significant.

Similar results were observed by these two studies. Bimla Sharma et $\mathrm{al}^{1}$ conducted a study of 100 consecutive cases of gynecological laparoscopic surgeries. The results showed the PLMA was easier to insert with high success rate on first attempt and required less time. Prerna et $\mathrm{al}^{5}$ showed that time required for insertion was shorter for PLMA as compared with ETT.

When pulse rate and MAP were compared between ETT and PLMA groups at all the time intervals, statistically

Table 3: Sore throat (ST) scale

\begin{tabular}{lllll}
\hline ST scale & & ETT & PLMA & Total \\
\hline Absent & No. & 31 & 37 & 68 \\
& $\%$ & 45.6 & 54.4 & 85 \\
Present & No. & 9 & 3 & 12 \\
& $\%$ & 60 & 40 & 15 \\
\hline
\end{tabular}

\begin{tabular}{lllll}
\hline Chi-square test & Value & $D f$ & $p$-value & Association \\
\hline Pearson's chi-square & 3.8 & 1 & 0.04 & $\mathrm{~S}$ \\
\hline
\end{tabular}

S: Significant 
significant differences were observed at insertion, 1, 3, 5, 10 minutes, after desufflation, and extubation. At all these time intervals, the hemodynamic changes were significantly less in PLMA group as compared with ETT group.

Though there was a statistically significant increase in the pulse rate and blood pressures from the baseline after endotracheal intubation, this difference is not clinically significant (not more than 20\% increase from the baseline).

Attenuation of the response to PLMA is due to diminished catecholamine release, as suggested by Lamb et al. ${ }^{6}$ This could in turn be due to the fact that LMA is relatively simple and atraumatic to insert and does not require laryngoscopy before insertion. Wood and Forrest ${ }^{2}$ assessed the hemodynamic response to the insertion of the LMA compared with that of laryngoscopy and tracheal intubation and also showed that the changes in all cardiovascular parameters measured following LMA insertion were significantly less $(\mathrm{p}<0.05)$ following laryngoscopy and tracheal intubation. They concluded that airway management with LMA may be used to avoid the hemodynamic response to tracheal intubation where such response is undesirable. ${ }^{7}$

Fuji et $\mathrm{al}^{8}$ also evaluated the hemodynamic changes of tracheal extubation or removal of a LMA. Changes in $\mathrm{HR}, \mathrm{MAP}$, and rate-pressure product were measured before and 1, 2, 3, 5, and 10 minutes after tracheal extubation or LMA removal. The study thus concluded that removal of LMA is associated with less cardiovascular change than tracheal extubation in both normotensive and hypertensive patients. ${ }^{9}$

\section{COMPARISON OF EtCO ${ }_{2}$ and $\mathrm{SpO}_{2}$}

In our study, the changes in $\mathrm{EtCO}_{2}$ after PLMA or ETT intubation, though statistically significant, had no clinical significance because the $\mathrm{EtCO}_{2}$ was maintained within normal limits. There was no significant increase in $\mathrm{EtCO}_{2}$ after $\mathrm{CO}_{2}$ insufflation. Similar results were quoted by Bimla Sharma et al. ${ }^{1}$ Prerna et $\mathrm{al}^{5}$ also evidenced maintenance of the $\mathrm{EtCO}_{2}$ within normal limits during the entire duration of the procedure. ${ }^{3}$

The PLMA formed an effective seal around the glottis as reported by previous workers, ${ }^{2,10-12}$ thus allowing adequate oxygenation before and after $\mathrm{CO}_{2}$ insufflation in all patients. In our study, no cases of failed ventilation were found in PLMA group. There were no episodes of desaturation noted with either the PLMA or ETT group.

\section{COMPARISON OF GASRTIC DISTENSION}

In our study, gastric distension was noted by direct vision with laparoscopic camera. Gastric insufflation was noted in six patients in ETT group and in five patients in PLMA group, but none of the patients in PLMA group required intubation with a view to avoid further distension.

Similar instances have been found by Maltby et $\mathrm{al}^{13}$ using PLMA. ${ }^{5,14-17}$ Chakraborty et $\mathrm{al}^{12}$ in their study compared gastric distension during laparoscopic cholecystectomy in 60 patients with either PLMA/ETT. They found that the incidence of gastric distension was lower with the PLMA than with the ETT.

\section{COMPARISON OF POSTOPERATIVE SORE THROAT}

In ETT group, nine patients had sore throat compared with three patients in PLMA group, which was statistically significant. Sore throat complaints were of mild to moderate grades and none of them required active management. Piper et $\mathrm{al}^{18}$ compared PLMA and ETT in gynecologic laparoscopies and concluded that PLMA was a safe and effective ventilation device with low stress imposed to patient and low occurrence of pharyngeal and laryngeal complications, especially the incidence of sore throat was less in PLMA than ETT.

Sore throat and dysphonia commonly occur after both endotracheal intubation and LMA insertion. The incidence of sore throat varies in different studies due to variation in size of LMA and ETT used in different studies, design and type of ETT used, lubricating material used. The cuff pressure of LMA and ETT, duration and $\%$ of nitrous oxide also matter in incidence of sore throat.

Perioperatively, no episodes of laryngospasm, bronchospasm, arrhythmias, hypertension, desaturation, and inadequate ventilation were observed in both the groups.

\section{CONCLUSION}

The PLMA is an equally effective and safe airway device to conventional tracheal intubation with controlled ventilation for gynecological diagnostic laparoscopy; it is more rapidly inserted and associated with an attenuated hemodynamic response to insertion and removal and has less gastric distension and laryngopharyngeal morbidity. ${ }^{19-31}$

\section{REFERENCES}

1. Sharma B, Sahai C, Bhattacharya A, Kumara VP, Sood J. ProSeal laryngeal mask airway: a study of 100 consecutive cases of laparoscopic surgery. Indian J Anaesth 2003;47(6);467-472.

2. Wood ML, Forrest ET. The haemodynamic response to the insertion of the laryngeal mask airway: a comparison with laryngoscopy and tracheal intubation. Acta Anaesthesiol Scand 1994 Jul;38(5):510-513.

3. Keane WM, Denneny JC, Rowe LD, Atkins JP Jr. Complications of intubation. Ann Otol Rhinol Laryngol 1982 Nov-Dec;91 (6 Pt 1):584-587.

4. Cook TM, Nolan JP, Verghese C, Strube PJ, Lees M, Millar JM, Baskett PJ. Randomized crossover comparison of the ProSeal 
with the classic laryngeal mask airway in unparalysed anaesthetized patients. Br J Anaesth 2002 Apr;88(4):527-533.

5. Shroff P, Surekha K. Randomized comparative study between the ProSeal laryngeal mask airway and the endotracheal tube for laparoscopic surgery. Internet J Anaesthesiol 2006; 11(1).

6. Rieger A, Brunne B, Hass I, Brummer G, Spies C, Striebel HW, Eyrich K. Laryngo-pharyngeal complaints following laryngeal mask airway and endotracheal intubation. J Clin Anesth 1997 Feb;9(1):42-47.

7. Maltby JR, Beriault MT, Watson NC, Fick GH. Gastric distension and ventilation during laparoscopic cholecystectomy: LMA-Classic vs. Tracheal intubation. Can J Anaesth 2000 Jul;47(7):622-626.

8. Fujii $Y$, Toyooka H, Tanaka H. Cardiovascular responses to tracheal extubation or LMA removal in normotensive and hypertensive patients. Can J Anaesth 1997 Oct;44(10):1082-1086.

9. Maltby JR, Beriault MT, Watson NC, Liepert D, Fick GH. The LMA-ProSeal is an effective alternative to tracheal intubation for laparoscopic cholecystectomy. Can J Anaesth 2002 Oct;49(8):857-862.

10. Piper, J. Physiological equilibria of gas cavities in the body. In: Fenn, WO, Rahn, M., editors. Handbook of physiology. Section 3: respiration. Washington, DC: American Physiological Society; 1965. p. 1205-1220.

11. Mullett CE, Viale JP, Sagnard PE, Miellet CC, Ruynat LG, Counioux HC, Motin JP, Boulez JP, Dargent DM, Annat GJ. Pulmonary $\mathrm{CO}_{2}$ elimination during surgical procedures using intra- or extraperitoneal $\mathrm{CO}_{2}$ insufflation. Anesth Analg 1993 Mar;76(3):622-626.

12. Chakraborty A, Kumar GP, Bhattacharya P. Gastric distension during laparoscopic cholecystectomy; comparison between ETT and PLMA. Internet J Anaesthesiol 2007;13(1).

13. Maltby JR, Beriault MT, Watson NC, Liepert DJ, Fick GH. LMA-Classic and LMA-ProSeal are effective alternatives to endotracheal intubation for gynaecological laparoscopy. Can J Anaesth 2003 Jan;50(1):71-77.

14. Chaurasia, BD. The larynx. In: The human anatomy, regional and applied. Vol. 3. p. 203-210.

15. Dorsch, JA. Tracheal tubes. Understanding anaesthesia equipment. p. 557-675.

16. Joris, JL. Anesthesia for laparoscopic surgery. In: Miller, RD., editor. Anesthesia. 7th edition. Philadelphia: Churchill Livingstone; 2009. p. 2185-2202.

17. Jones MJ, Mitchell RW, Hindocha N. Effect of increased intra-abdominal pressure during laparoscopy on the lower esophageal sphincter. Anesth Analg 1989 Jan;68(1):63-65.
18. Piper SN, Triem JG, Röhm KD, Maleck WH, Schöllhorn TA, Boldt J. ProSeal-laryngeal mask versus endotracheal intubation in patients undergoing gynaecologic laparoscopy. Anaesthesiol Intensivmed Notfallmed Schmerzther 2004 Mar;39(3):132-137.

19. Brain AI. The laryngeal mask: a new concept in airway management. Br J Anaesth 1983 Aug;55(8):801-805.

20. Brimacombe JR, Berry A. The incidence of aspiration associated with the laryngeal mask airway: a meta-analysis of published literature. J Clin Anesth 1995 Jun;7(4):297-305.

21. Brain AI, Verghese C, Strube PJ. The LMA "ProSeal" - a laryngeal mask with an oesophageal vent. Br J Anaesth 2000 May;84(5):650-654.

22. Sood J, Jayaraman L, Kumra VP. Endoscopic surgeryanaesthetic challenges - a historical review. Indian J Anaesth 2006 May;50(3):178-182.

23. Keller C, Brimacombe J, Kleinsasser A, Loeckinger A. Does the ProSeal laryngeal mask airway prevent aspiration of regurgitated fluid? Anesth Analg 2000 Oct;91(4):1017-1020.

24. Lu PP, Brimacombe J, Yang C, Shyr M. ProSeal versus the Classic laryngeal mask airway for positive pressure ventilation during laparoscopic cholecystectomy. Br J Anaesth 2002 Jun;88(6):824-827.

25. Brain, AIJ. The Intavent laryngeal mask: instruction manual. Intavent Orthofix; 1993.

26. Keller C, Brimacombe J. Mucosal pressure and oropharyngeal leak pressure with the ProSeal versus laryngeal mask airway in anaesthetized paralysed patients. Br J Anaesth 2000 Aug;85(2):262-266.

27. Brimacombe J, Keller C. The ProSeal laryngeal mask airway: a randomized, crossover study with the standard laryngeal mask airway in paralyzed, anesthetized patients. Anaesthesiologists 2000 Jul;93(1):104-109.

28. Grady DM, McHardy F, Wong J, Jin F, Tong D, Chung F. Pharyngolaryngeal morbidity with the laryngeal mask airway in spontaneously breathing patients: does size matter? Anesthesiology 2001 May;94(5):760-766.

29. Tan SM, Sim YY, Koay CK. The ProSeal laryngeal mask airway size selection in male and female patients in an Asian population. Anaesth Intensive Care 2005 Apr;33(2):239-242.

30. Lind JF, Warrian WG, Wankling WJ. Responses of the gastroesophageal junctional zone to increases in abdominal pressure. Can J Surg 1966 Jan;9(1):32-38.

31. Lim Y, Goel S, Brimacombe JR. The ProSeal laryngeal mask airway is an effective alternative to laryngoscope-guided tracheal intubation for gynaecological laparoscopy. Anaesth Intensive Care 2007 Feb;56:38-39. 